\title{
A IMPORTÂNCIA DO INTÉRPRETE DE LIBRAS NA EDUCAÇÃO BÁSICA
}

\section{LA IMPORTANCIA DEL INTÉRPRETE DE LA LIBRAS EN LA EDUCACIÓN BÁSICA}

\section{THE IMPORTANCE OF THE LIBRAS INTERPRETER IN BASIC EDUCATION}

Ediangela Soares Silva do Nascimento ${ }^{1}$; Henllayane Nathani de Amorim Amaral ${ }^{2}$; Rafaela Alcântara Barros de Oliveira ${ }^{3}$

DOI: https://doi.org/10.31692/978-65-991061-3-2.158-162

\section{INTRODUÇÃO}

O intérprete de Libras convive com diversos conflitos, aceitação e lutas pela pessoa surda, ele está ligado à inclusão na sociedade, ambiente esse pouco receptivo. O reconhecimento das Libras como Língua é recente, mesmo em toda a sua complexidade, se tornou real e obrigatória, através da Lei $n^{\circ}$ 10.436/2002, estabelecida originalmente no art. 4 o ensino da Língua Brasileira de Sinais - Libras, como parte integrante dos Parâmetros Curriculares Nacionais - PCNs, conforme legislação vigente (BRASIL, 2002). São notáveis os avanços relacionados à pessoa com surdez, através de legislações que efetivaram a interação dos indivíduos surdos com a sociedade. Esse direito foi concretizado através do Decreto n. 5.626/2005, art. 2 em que se considera pessoa surda aquela que, por ter perda auditiva, compreende e interage com o mundo através de experiências visuais, manifestando a sua cultura principalmente pelo uso da Língua Brasileira de Sinais — Libras (BRASIL, 2005).

Ações levaram as pessoas com surdez à sala de aula, e a partir daí que o intérprete contribui no ensino da língua aos estudantes surdos na escola. Leis foram criadas, especificando como deve ser o modo de ensino-aprendizagem, estabelecendo normas e critérios para o acesso das pessoas com deficiência auditiva à comunidade, a partir desse momento as escolas passaram a serem alvos de colocação desses profissionais.

A inclusão da criança surda na escola, não é trata-la de forma diferente aos demais estudantes, consistem em desenvolver o potencial dessas crianças respeitando as diferenças e atendendo as suas necessidades. Para que os estudantes com limitações auditivas tenham um aprendizado completo, a escola deverá incluir no seu material didático, ferramentas visuais e todos os tipos de estímulos para que haja mais interação na sala de aula por parte destes estudantes. (DAMAZIO, 2007, p. 26). Por não participar de uma formação de qualidade o

\footnotetext{
${ }^{1}$ E-mail: ediangelacbio@gmail.com

${ }^{2}$ E-mail: Henllayane16@gmail.com

${ }^{3}$ E-mail: Alcantara.rafaela14@gmail.com
} 
intérprete por diversas vezes ensinava com o conhecimento básico e os materiais que continha em sala de aula para que a aprendizagem se tornasse ativa. Gradativamente as instituições de ensino foram adaptando-se as normas estabelecidas, com os cursos formadores de intérpretes.

\section{FUNDAMENTAÇÃO TEÓRICA}

A educação para surdos começou a ter avanços, porém, o preconceito ainda está presente, a visão deturpada que foi construída contribui para a ideia de que são pessoas incapazes intelectualmente de assimilar o que lhe é proposto, realizar atividades e ocupar cargos importantes. Aquele que não ouve tão bem, ou não percebe algumas manifestações sonoras na medida em que deveria, frequentemente passa a ser distinguido como alguém com perda, com carência, com falta de, com deficiência e como pessoa portadora de uma especificidade (LULKIN, 1998, p. 40). A população ainda não compreendeu que a limitação que a pessoa com surdez apresenta é a falta de audição. A língua de sinais ocorre para os surdos assim como a língua oral para os ouvintes. São suas vozes, é através dos seus olhos que observam o mundo ao seu redor, não falta nada a eles, pelo contrário, os tornam especiais (LABORIT, 1994).

A maior parte das crianças surdas assim como também os jovens e adultos podem aprender a língua de sinais, participando da vida cotidiana e com a comunidade surda, isso ocorre de maneira natural, espontânea, assim como ocorre na linguagem oral, porém, apesar de ser uma prática comum não é unânime. Essa maneira natural de aprender a linguagem de sinais passa de geração a geração, e que vai mudando com o passar dos tempos (SKLIAR, 1998). Um dos motivos da existência de uma barreira entre surdos e ouvintes é a dificuldade de comunicação provocando por diversas vezes a falta de inclusão, por exemplo, na educação básica Língua Brasileira de Sinais não faz parte do componente curricular como, por exemplo, a Língua Portuguesa. Surdos e ouvintes têm línguas diferentes, mas podem viver numa única comunidade, desde que haja um esforço mútuo de aproximação pelo conhecimento das duas línguas, tanto por ouvintes como por surdos (ALMEIDA, 2000, p.3).

Segundo (GOLDFELD, 2002), a linguagem de sinais não se difere muito das linguagens orais, da mesma forma que as pessoas comuns riem, brincam, contam piadas, e nem por isso eles se olham diferentes.

Lacerda (2002) ressalta que a escola é o local onde é realizado o trabalho de interação do intérprete com os demais profissionais e por diversas vezes acredita-se que apenas com a presença desse profissional é possível sanar os problemas relacionados à inclusão da criança surda, mas, ao decorrer do tempo e através de reflexões cautelosas é perceptível que apesar da possibilidade de comunicação, certos problemas e lacunas permanecem como, por exemplo, 
ajustes curriculares e metodológicos.

Gurgel (2010) reforça que por causa da recente regulamentação da profissão, a formação dos intérpretes que atuam na educação é bastante heterogênea e com poucas alternativas. Somente em 2010 através da Lei n 12.319 foi regulamentado o exercício da profissão de tradutor e intérprete de Libras, no art. 4 contém que a sua formação deve ser realizada através de cursos de educação profissional, extensão universitária e formação continuada.

A comunidade surda vem empenhando-se pela defesa dos seus direitos, com o reconhecimento das Libras como língua potencializou avanços nessas conquistas. A inserção da Língua Brasileira de Sinais no currículo da educação básica, assim como o profissional intérprete traria benefícios também na evolução da aprendizagem das crianças surdas, pois, desta maneira a inclusão seria mais efetiva. O ensino da Língua de Sinais deveria ser obrigatório para todos, surdos e ouvintes. Repensar as práticas de como lidar com a surdez na escolarização das pessoas surdas, torna-se urgente mostrar a elas que a dificuldade de aprendizagem não vem delas, mas sim do modo como a escola através de práticas pedagógicas possam ensiná-los (SILVA, 2007).

\section{METODOLOGIA}

A partir do método qualitativo foi utilizada como procedimento metodológico, a pesquisa bibliográfica através de livros, artigos e legislações referentes à educação de surdos com o intuito de compreender a importância da formação de intérpretes da Língua Brasileira de Sinais (LIBRAS) no ensino básico para o desenvolvimento da comunicação e expressão das crianças surdas. Quando investigamos o entendimento das pessoas a respeito de vários fenômenos, conceitos e princípios, nós repetidamente achamos que cada fenômeno, conceito ou princípio pode ser entendido qualitativamente de diferentes maneiras (MARTON, 1986, p.31).

Após leituras referentes à formação de intérpretes para educação de surdos, foi realizado um levantamento qualitativo, num estudo exploratório de modo a expor fundamentos plausíveis, relatando o ponto de vista dos autores pesquisados, bem como as legislações relacionadas com o tema, identificando quais as dificuldades desses profissionais em atender as necessidades dos estudantes surdos.

\section{RESULTADOS E DISCUSSÕES}

O profissional intérprete é indispensável para o desenvolvimento da comunicação e inclusão da pessoa surda na sociedade, à inserção do intérprete de Libras na educação básica 
necessita de planejamento por parte das escolas através de metodologias ativas que permitam desenvolver além da expressão desse estudante a qualidade do ensino. De acordo com Lacerda (2000, p. 57):

a presença do intérprete não assegura que questões metodológicas, levando em conta

a surdez e os processos especiais/próprios de acesso ao conhecimento sejam considerados, ou que o currículo escolar sofra ajustes para contemplar peculiaridades e aspectos culturais da comunidade surda.

É preciso que a formação do intérprete educacional seja interdisciplinar voltada à prática da mediação da aprendizagem, visto que, para interpretação de conteúdos específicos é necessário um profundo conhecimento teórico sobre cada área do conhecimento, desenvolvida na escola, além da interação com os demais profissionais para construir a melhor maneira de aprendizagem.

\section{CONCLUSÕES}

A língua de sinais é um elemento mediador na educação promovendo inclusão desses estudantes na sociedade. O intérprete atualmente exerce a função de auxiliar no processo de desenvolvimento educacional, é o canal comunicativo entre surdos e ouvintes em que na maioria das situações ele é o único que conhece a língua do ambiente escolar.

Portanto, conclui-se que apesar de a responsabilidade do aprendizado do estudante com limitação auditiva na sala de aula ser do professor, o intérprete é indispensável, pois, promove a mediação dos conteúdos programáticos, bem como a interação social desse estudante. Com isso é essencial que esse profissional obtenha uma formação de qualidade para sanar as necessidades dos estudantes durante o processo de construção do conhecimento e comunicação na sala de aula.

\section{REFERÊNCIAS}

DAMAZIO, Mirlene Ferreira Machado. Atendimento educacional especializado: pessoa com surdez. São Paulo: MEC/SEESP, 2007.

ALBRES, Neiva de Aquino. Intérprete Educacional: políticas e práticas em sala de aula inclusiva. São Paulo: Harmonia, 2015.

ALMEIDA, Elizabeth Oliveira Crepaldi de Almeida. Leitura e Surdez: um estudo com adultos não oralizados. Rio de Janeiro: Revinter, 2000.

BRASIL. Lei $\mathbf{n}^{\mathbf{0}} \mathbf{1 0 . 0 9 8}$, de 19 de dezembro de 2000. Disponível em http://www.planalto.gov.br/ccivil_03/leis/L10098.htm. Acesso em 15 de ago. de 2019. 
BRASIL. Decreto no 5.626, de 22 de dez. 2005. Presidência da república, Casa Civil, Brasília, DF, 22 de dez. 2005. Disponível em http://www.planalto.gov.br/ccivil_03/_ato20042006/2005/decreto/d5626.htm. Acesso em 15 de ago. de 2019.

GOLDFELD, Marcia. A criança surda: linguagem e cognição numa perspectiva sociointeracionista. 7. ed. São Paulo: Plexus Editora, 2002.

GURGEL, T. M. A. Práticas e formação de tradutores intérpretes de língua brasileira de sinais no ensino superior Tese. (Doutorado em Educação). Universidade Metodista de Piracicaba. Piracicaba-SP. 2010.

LABORITT, Emmanuelle. O vôo da gaivota. São Paulo: Best Seller, 1994.

LACERDA, Cristina Broglia Feitosa; GÓES, Maria Cecília Rafael. O intérprete educacional de língua de sinais no ensino fundamental: refletindo sobre limites e possibilidades. In: LODI, Ana Cláudia Balieiro et al. (Org.). Letramento e Minorias. Porto Alegre: Mediação, 2002. P. 120-128.

LACERDA, C. B. F. A prática pedagógica mediada (também) pela língua de sinais: trabalhando com sujeitos surdos. Cad. CEDES, 2000.

LACERDA, Cristina Broglia Feitosa. Intérprete de Libras: em atuação na educação infantil e no ensino fundamental. Porto Alegre: Mediação, 2009.

LULKIN, Sérgio Andrés. O discurso moderno na educação dos surdos: práticas de controle do corpo e a expressão cultural amordaçada. In: SKLIAR, Carlos. A surdez: um olhar sobre as diferenças. Porto Alegre: Mediação, 1998. p. 33-50.

MARTINS, Vanessa Regina de Oliveira. Educação de Surdos no Paradoxo da Inclusão com Intérprete de Língua de Sinais: relações de poder e (re)criações do sujeito. 2008. 140 f. Dissertação (Mestrado em Educação) - Programa de Pós- -Graduação em educação, Universidade Estadual de Campinas, Campinas, 2008.

MARTON, F. Phenomenography - A research approach to investigating different understandings of reality. Journal of Thought, 1986. p. 28-49.

SILVA, Fabio Irineu et al. Aprendendo a Língua Brasileira de Sinais como segunda língua. Palhoça: IFSC - Campus Palhoça/NEPES, 2007.

SKLIAR, Carlos (Org.). A Surdez: um olhar sobre as diferenças. Porto Alegre: Mediação, 1998. 